\title{
METHOD OF RESEARCH FOR SOLAR COOKERS PERFORMANCE CHARACTERISTICS- ANALYSIS AND COMPARISON
}

\author{
Geetanjali Raghav* \\ University of Petroleum \& Energy Studies, Dehradun, India, \\ email: graghav@ddn.upes.ac.in \\ Anjali.1109@gmail.com \\ Pankaj Kumar Sharma \\ University of Petroleum \& Energy Studies, Dehradun, India \\ Suresh Kumar \\ Shri Vishwakarma skill University, India \\ Rajesh Maithani \\ University of Petroleum \& Energy Studies, Dehradun, India
}

Article history: Received 19 May 2021, Received in revised form 12 June 2021, Accepted 12 June 2021, Available online 14 June 2021.

\begin{abstract}
Cooking is one of the most common activity in day-to-day life of every woman. In rural areas the transportation of fuel is major problem and the increasing demand of energy for cooking applications is gaining importance and various investigations are being carried out for performance enhancement of the solar cooker. The box-type solar cooker has a complex thermal analysis due to the transient heat transfer phenomenon involved in three dimensions. A comparison of the standard correlation available are analysed for accuracy of predicted results with experimental data. The investigation involves the experimental determination of the parameters viz. wind heat transfer coefficient, side and bottom loss coefficient, inner and outer glass temperature. The extensive data is analysed with that of standard correlations and the significance of the experimental data is checked. Analysis found to have deviation of $3 \%-20 \%$ in experimental and correlation data, which indicates that for accuracy of performance analysis the studied parameters should be determined experimentally.
\end{abstract}

\section{Keywords}

solar cooker, cooking, plate temperature, thermal performance

\section{Nomenclature}

A aperture area of cooker $\left(\mathrm{m}^{2}\right)$

$A_{p} \quad$ aperture area of absorber plate of unglazed test plate $\left(\mathrm{m}^{2}\right)$

$\mathrm{C}_{\mathrm{p}} \quad$ specific heat of unglazed test plate $(\mathrm{J} / \mathrm{kgK})$

$h_{w} \quad$ wind heat transfer coefficient $\left(\mathrm{W} / \mathrm{m}^{2} \mathrm{~K}\right)$

I instantaneous value of solar radiation $\left(\mathrm{W} / \mathrm{m}^{2}\right)$

$k \quad$ thermal conductivity of air $(\mathrm{W} / \mathrm{mK})$

$k_{a} \quad$ thermal conductivity of cement asbestos ( $(\mathrm{W} / \mathrm{mK})$

$k_{g w} \quad$ thermal conductivity of glass wool $(\mathrm{W} / \mathrm{mK})$

$L \quad$ thickness of glass cover $(m)$

$L_{1} \quad$ air gap spacing between absorber plate and inner glass cover $(m)$

$L_{2} \quad$ air gap spacing between inner and outer glass cover $(m)$

$a_{L} \quad$ thickness of asbestos sheet $(m)$

$L_{c s} \quad$ thickness of cement slab $(m)$

Lgw thickness of glass wool $(m)$

$Q_{a} \quad$ rate of heat absorbed by test plate per unit area $\left(\mathrm{W} / \mathrm{m}^{2}\right)$

$Q_{b^{\prime \prime}} \quad$ bottom heat loss flux $\left(W / m^{2}\right)$

$Q_{c} \quad$ rate of convective heat loss per unit area of test plate $\left(W / \mathrm{m}^{2}\right)$

$Q_{r} \quad$ rate of radiative heat loss per unit area of test plate $\left(W / \mathrm{m}^{2}\right)$

$Q_{s} \quad$ Sensible heat absorbed rate to test plate temperature rise per unit area $\left(W / \mathrm{m}^{2}\right)$

' $T_{p} \quad$ thickness of test plate $(m)$ 
$T_{\text {as }} \quad$ ambient temperature at stagnation $(K)$

Tp average test plate temperature $(K)$

$T_{m p 1} \quad$ mean temperature of absorber plate and inner glass cover $(K)$

$T_{m 12} \quad$ mean temperature of inner and outer glass cover $(K)$

$U_{L} \quad$ overall heat loss coefficient $\left(\mathrm{W} / \mathrm{m}^{2}{ }^{\circ} \mathrm{C}\right)$

$U_{t} \quad$ top heat loss coefficient $\left(\mathrm{W} / \mathrm{m}^{2}{ }^{\circ} \mathrm{C}\right)$

$U_{b} \quad$ bottom heat loss coefficient $\left(W / \mathrm{m}^{2}{ }^{\circ} \mathrm{C}\right)$

$U_{s} \quad$ side heat loss coefficient $\left(W / \mathrm{m}^{2}{ }^{\circ} \mathrm{C}\right)$

$\alpha_{p} \quad$ absorptivity of the test plate

$\varepsilon_{\mathrm{p}} \quad$ emissivity of the test plate

$\varepsilon g \quad$ emissivity of glass

$\rho \quad$ mass density of test plate $\left(\mathrm{kg} / \mathrm{m}^{3}\right)$

$\sigma \quad$ Stefan-Boltzmann constant $\left(\mathrm{W} / \mathrm{m}^{2} K^{4}\right)$

$d T \quad$ difference of temperature of test plate during the time interval (sec)

$T_{\text {it }} \quad$ top insulation temperature of the test plate $(K)$

$T_{i b} \quad$ bottom insulation temperature of the test plate $(K)$

\section{Introduction}

The demand for cleaner and sustainable energy resources in the present scenario leads to the use of solar energy as an effective alternative to conventional fossil fuels. As the food is required on daily basis and by everyone thus if the utilization of solar cooking is taken up by a large population, then a huge amount of energy required from fossil fuel can be saved. The basic principle of solar cooking is based on the extraction of solar energy and its conversion to heat and its conduction to the cooking pot. Continuous investigations are being carried out to bring out a design of solar cooker that proves to be highly effective and with a better performance. Various geometrical and operating parameters are investigated by researchers to fulfil the aim. Thermal performance testing is one of the most prominent aspects of box-type solar cooker. A lot of research was focused on improving their efficiencies of various types of solar cookers such as concentrating type, parabolic, panel solar cookers, cookers with variation in shapes or geometry as square and rectangular and cookers with storage.

The first thermal performance analysis was led by VITA [1], Volunteers in Technical Assistance (VITA) the evaluation was on different measures, for example, cooking execution, strength, cost, weight, straightforwardness to move simplicity of activity, simplicity of assembling and versatility to local aptitudes and materials. Different techno monetary psychological factors scaled on 100 pointer scale was evaluated by an examination announced by Bowman and Blatt [2], the transient model for a single glazed box type solar cooker was proposed by Garg et al.[3] predicted the temperature profile for various elements of the cooker. That transient model included a simple steady-state model of a solar cooker neglecting heat capacity terms. The values obtained theoretically were much higher than the observed values from the experiments. Certain improvements were added by Vaishya et al. [4] in a box-type solar cooker with certain improvements in the form of the double glass cover and a plane reflector, keeping it horizontal in sunlight with reflector vertical. Data were recorded and analyzed for the highest temperature for different months at Delhi. Literature by Kandpal and Mathur [5] reported having a study on the economic feasibility of using a simple box-type solar cooker using simple engineering economics and represented it graphically using certain numerical calculations. The major contribution was reported by Mullick et al. [6]. The researchers proposed a new performance parameter named as the first and second figure of merit $F 1$ and $F 2$, respectively of box-type solar cookers. The methodology presented includes the no-load stagnation test and full load water boiling test to find $F 1$ and $F 2$ of box type solar cookers. The above method was extremely helpful and given a proper method to look at the presentation of various kinds of sun-oriented cooker. Chaaniwala and Doshi [7] developed a correlation for top heat loss coefficient based on indoor experimental data. The proposed correlation was based on the analysis that the heat loss coefficient of a solar box cooker directly varies with plate temperature and wind velocity. Jurban and Alsaad [8] were reported to develop a theoretical model for single- and double-glazed box-type solar cookers with or without reflectors. The mathematical model was created using a heat balance analysis of the various components of the cooker, the variation of various parameters such as material composition properties and the overall heat loss coefficient as a function of the absorber plate and temperature of the food item. The results of the theoretical investigation were and conform reasonably to available experimental results.

An improved strategy to evaluate the top heat loss factor of flat plate collector with single coating and twofold coating was accounted for by Mullick and Samdarshi [9]. The values of heat loss factor at the top were less than 
three percent of the values acquired by the iterative arrangement of the energy balance condition for single glazing. Thus, for authorities with twofold coating, the values of top heat loss factor were less than three percent contrasted with numerical arrangement of the warmth balance condition for twofold coating. Suharta et.al [10] devoted three years in Indonesia in promotion of solar cookers. A mathematical model speaking to the heat transfer forms required inside a box-type sunlight-based cooker, containing nourishment, was created by Pejack [11]. The outcomes announced that the nourishment temperature was influenced by scope, month, wind, mists, nourishment amount, thermal obstruction of the sides of the case and direction of the box during cooking. Mullick et al. [12] have also proposed the testing procedure for paraboloid-type solar cookers. While the impact of wind on the exhibition of paraboloid type concentrator sun powered cookers was talked about by Kumar and Kishor [13]. Das et al. [14] created thermal models for the solar box-cookers stacked with one, two, or four vessels. A thermal model was proposed by Thulsi Das et al. [15] for box type solar cooker with one to four vessel variation using heat transfer coefficient as main parameter calculated experimentally. Research also proposed that stainless steel and aluminum vessels can be used with black paint. Said and Medhat [16] recommended formulae for calculating orientation angle and tilt angle of the reflector of the sun-based cooker. El-Sebaii et al.[17] literature answered to build up a mathematical model for a box type sunlight-based cooker with external and inward reflectors. The performance of the cooker was researched utilizing a PC simulation as characteristics and specific boiling time. Sharan and Naik [18] endeavored to find the socio-psychological components determining the acknowledgment of SBCs in India. In Brunei Darussalam, a program to create, test and evaluate a sun powered cooker was done.

Various studies were carried out on the analyses of the effect of the number of pots and different load conditions. Mullick et al. [19] recommended that that the cooker must be tested with full load distributed equally in all pots based on the test results for box-type solar cooker with different loads and number of pots. The performance of the box-type solar cooker with auxiliary heating was studied and reported by Hussein [20], using heating oil to provide continuous supply during cloudy days.

Nandwani [21] reported the performance of two solar box cookers with two similar compartments and compared the behavior of a metallic slab filled with a phase change material for short term heat storage, with a conventional absorbing sheet, the use of a selective coating, as compared to a normal black painted. Amer et al. [22] experimentally evaluated four procedures to test solar cookers and analyzed the results and compared them in steady-state condition-based ASHRAE 93-86 standard. The experimental results have been compared with Saunier's method, ASHRAE standard and Exell's method.

Literature reported by Amer et. Al [23] built up a transient model with an intends to describe the dynamic conduct of flat plate sun-powered collector- based utilizing model of one node where the mean temperature is evaluated considering the heat capacity of the plate, cylinders, and the fluid, lumped together. On the other hand, Funk and Larson [24], proposed a model for estimation of the cooking intensity of a sun-based cooker dependent on sun-powered catch territory, overall heat transfer coefficient, and absorber plate thermal conductivity is known as three controlled factors and three uncontrolled factors insulation, temperature distribution and load distribution.

Gaur et al. [25] proposed a cooking vessel that gave a sunken cover. Their experimental investigation demonstrated a decrease of $10-13 \%$ in cooking time contrasted with and standard cooking vessels under similar conditions. Biermann et al. [26] conducted experiments on seven distinct types of sun-powered cookers for one year which include around 66 families in South Africa, the results revealed that the Fuel utilization estimations show overall fuel reserve funds of $38 \%$, coming about in assessed take care of periods (through monetary fuel investment funds) from multi-month onwards, contingent upon the sort and area. Akhtar and Mullick [27] proposed correlations for the estimation of heat loss coefficients in sun-based collectors with single glazing. Semi-analytical amendment factor ( $f$ ) was utilized as the proportion of internal to external heat loss coefficients as a component of collector parameters and ambient variable. They also proposed a method for precise estimation of glass cover temperatures, individual heat transfer coefficients and top heat loss factor of flat plate sun-based collectors with single and two-fold glazing without the necessity of arrangements of heat balance conditions. Funk [28] had distinguished five uncontrolled factors wind, ambient temperature, pot substance temperature, insolation and sun powered altitude-azimuth and three controlled factors loading, tracking, temperature detecting influencing cooker performance. Sharma et al. [29] developed and performed the thermal analysis an imaginative design of sun-powered cooker in which there were isolated parts for energy collection and cooking along with a capacity unit utilizing commercial evaluation erythritol as storage liquid. It was seen that early afternoon cooking has no impact on night cooking and night cooking utilizing heat storage was seen as quicker than early afternoon cooking. The cooker performance under a variety of working and climatic conditions was learned at Mie, Japan. Suharta et al. [30] compared three Indonesian solar cookers, namely the newest 
design HS 5521 with HS 7033 and HS 5521 with and without the load of heat collection rate and of cooking performance. Mullick et al. [31] analyzed the effect of some of the parameters such as optical efficiency, the latitude of location, season on the performance of box-type solar cookers. Shaw [32] compared the different Test standards for solar cookers. Right now, there are three significant testing standards for sunlight-based cookers utilized all through the world. These standards contrast generally in their degree, unpredictability, and expectations. Ekechukwu and Ugwuoke [33] had reported that the performance of the cooker with a plane reflector in place was improved tremendously as compared to that without the reflector.

Amer [34], experimentally researched the exhibition of a double exposure sun-powered cooker, which was exposed to radiation from the top and base with a set of the plane diffuse reflectors. The presentation was contrasted with the conventional sun-oriented cooker under the same environmental conditions. Results

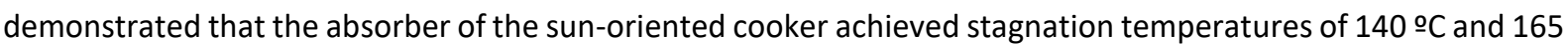
oC individually. The structure of the sunlight-based cooker was improved where the safeguard is presented to sun-powered radiation from the top and the base sides. Along with the plane diffuse reflectors with a reason to coordinate the radiation onto the base side of the safeguard plate. The exhibitions of the improved plan were contrasted and the conventional one utilizing heat balance condition. Results revealed that the safeguards of the case type cooker and the twofold presentation cooker achieved a temperature of $140^{\circ} \mathrm{C}$ and $165^{\circ} \mathrm{C}$ respectively, it was also seen that cooking time was diminished by around 30-60 min. Abdullah et al. [35] modified the designs, constructed, and tested two full tracking solar cookers, a paraboloid dish solar cooker (PDSC) and a booster mirror solar box cooker (BMSBC) to compare the performance under the same operating conditions. It was reported that the cooking rate was higher in paraboloid dish type solar cooker as compared to others, it can also cook well during intermittent conditions of sunny and cloudy days. The thermal execution also indicated a decrease of 24 to $35 \%$ in the heat loss from the recipient within the sight of the windshield. Nahar et al. [36] developed and performed the investigation on the performance of box stockpiling sun-oriented cooker with utilized engine as storage material utilizing stagnation temperature as one parameter so cooking can be performed in late night. The effectiveness of the hot box storage type sunlight-based cooker was seen as 27. Suresh et al. [37] proposed a semi-log plot method and an approximate method to find $F 2$ known as second figure of merit of box-type solar cookers. Ibrahim and Medhat [16] used the standard procedure of cooking power and analyzed a box type solar cooker to adjust four cooking pots under different weather conditions prevailing at in Tatna (Egypt) during July 2002. The cooker has the ability to cook variety of food with a utilization efficiency of $26.7 \%$. A simple test procedure for the determination of various design parameters was proposed by Kumar [38] used for the prediction of thermal performance of box-type solar cooker. Based on the experimental analysis, a correlation for the second figure of merit as a function of load was proposed. The experimental and calculated $F 2$ values were found in proximity.

A cylindrical single glazed with a plane reflector box-type sun-powered cooker with one cooking pot was developed and tried by Kurt [39] under the predominant climate conditions in Karabuk, Turkey. Nandwani [40] designed and analyzed a half-breed multi-reason sunlight-based cooker, which is utilized for food making, for warming up the water to inactivate organisms and refining procedures to evacuate different minerals and items drying. Schwarzer and Vieira da Silva [41] analyzed general sorts of sun-oriented cookers, their fundamental attributes, and experimental systems to test the various kinds of sun-powered cookers, and they proposed a simplified analytical model to plan a basic cooking framework. Literature suggested by Kurt et al. [39] reported using ANN for the purpose of prediction of thermal performance parameters of the experimentally investigated box-type solar cooker.

Arezki et al. [42] proposed a modification in the shape of the cooking vessel to reduce the cooking time, which further can improve heat transfer to the food through the pot walls.

Grupp et al. [43] developed to record food temperature, atmospheric temperature, and solar radiation incident on a solar cooker and evaluated the number of the cooking cycle, cooking times and food mass. The results were compared with actual conditions for box-type and concentrating solar cookers. Performance evaluation of two different types of solar cooker viz. rectangular and square box type was conducted by Garba [44] at Usmanudanfodiyo University Energy Research Centre, observations revealed that the rectangular box type cooker performed better than the square type. Dasin et al. [45] performed an evaluation of a parabolic concentrator type solar cooker in Abubakar Tafawa Balewa University Bauchi in Nigeria, results reported that attainment of stagnation temperature was achieved on three different days during June and July, it was also observed that it took 75 mins to boil 200g of white rice. Pinar [46] analyzed and compared the performance of box- type solar cookers with and without thermal energy storage using as storage material as Bayburt stone due to its low density and notably high specific heat capacity, in prevailing climatic conditions at Bayburt, Turkey, 
results indicated a considerable improvement in the performance of solar cooker. Geddam et al. [47] worked on experimental analysis experimentally obtained $F 2$ using a test procedure to determine these parameters under different load conditions of water and used the procedure to generate heating characteristic curves.

Manuel et al. [48] proposed a revision and formulated the revision in the existing standards i.e., figures of merit used for solar cooker thermal performance evaluation using easily variable and sorted instrumentation allowing these tests applicable anywhere in the World, with a minimum investment along with simple lab conditions. S. Bhavani et al. [49] worked on certain funny logic rules while analyzing the thermal performance of a box-type solar cooker with respect to the local climate prevailing at Chennai. Different tests were performed using this logic on the solar cooker. The sun-based cooker was equipped with PCM $\left(\mathrm{C}_{18} \mathrm{H}_{36} \mathrm{O}_{2}\right)$ and Nanoparticles $\left(\mathrm{Al}_{2} \mathrm{O}_{3}\right)$. Certain researchers raised the concern of fire in the buildings, and the main reason observed was cooking application [50] solar cookers are safe to operate and have negligible fire concern as they are operated in an open environment.

The literature review reveals that almost all the investigations are carried out using the standard correlation available for wind-heat transfer coefficient, side heat loss coefficient, outer glass cover temperature and inner glass cover temperature. The experimental analysis of any type of cooker should be carried out by calculating these parameters experimentally for accuracy in the results. The present investigation addresses these setbacks of correlation results and suggests experimental examination of standard data collection.

The present study involves a comparison of experimental and correlations data of selected climatic and operating variables, which affect the thermal performance parameters such as plate temperature, wind-heat transfer coefficient, side heat loss coefficient, outer glass cover temperature and inner glass cover temperature.

\section{Methods}

Description of the experimental setup

To determine the performance of the solar cooker an experimental facility has been designed and fabricated as per the BIS standard [51]. The photographic view of the experimental box-type solar cookers set up along with the test plate and its specifications are shown in Figure 1 and Table 1, respectively. The solar cooker has the dimension of (length $\times$ width $\times$ height) of $980 \times 980 \times 98(\mathrm{~mm})$, respectively, made of $12 \mathrm{~mm}$ plyboard $(\mathrm{k}=0.1154$ $\mathrm{W} / \mathrm{mK})$. The absorber plate of the cooker is made up of aluminum sheet and painted with blackboard paint. The bottom and the sides of the cooker are well insulated by using glass wool ( $k=0.037 \mathrm{~W} / \mathrm{mK})$. The air spacing between the plate and inner glass cover is $98 \mathrm{~mm}$ and that between glass covers is $12 \mathrm{~mm}$. Temperatures at 21 locations were measured with the help of calibrated Chromel Alumel (K-type) thermocouples to ascertain the accuracy of temperature measurement, thermocouples have been calibrated under laboratory conditions against a dry block temperature calibrated instant. (Presys Instruments T-25 N), having least count of $0.01{ }^{\circ} \mathrm{C}$. Pre-calibrated chromel-alumel thermocouples were fixed at the center of the absorber plate, inner and outer glass surface of both glass covers, at the center of glass wool insulation layers of $25 \mathrm{~mm}$ each with an objective to calculate the bottom and side losses. Solar radiations were recorded by pyranometer (KIPP and ZONEN). The stagnation test experiments to determine the thermal performance of the cooker have been conducted and the environmental temperature was measured at the site of the experiments. The experimental solar cooker and the unglazed test plate were kept side by side at the same height to minimize the uncertainty due to $h w$.

The outdoor experiments have been conducted on the rooftop of center for alternate energy at UPES on clear sunshine days. The experiments have been performed covering a change of season in January to December excluding July and August as they are heavily rained months in the Dehradun region in India. The testing of the solar cookers has been carried out as per BIS standard [51].

To evaluate the effect of various parameters on the performance of box-type solar cooker, various parameters (Table 2) were measured and recorded in UPES data logging software customized for the setup.

The cost of fabrication of the cooker was economical and estimated to be around INR1000, which is feasible and economical for the population residing in hilly and remote locations. 


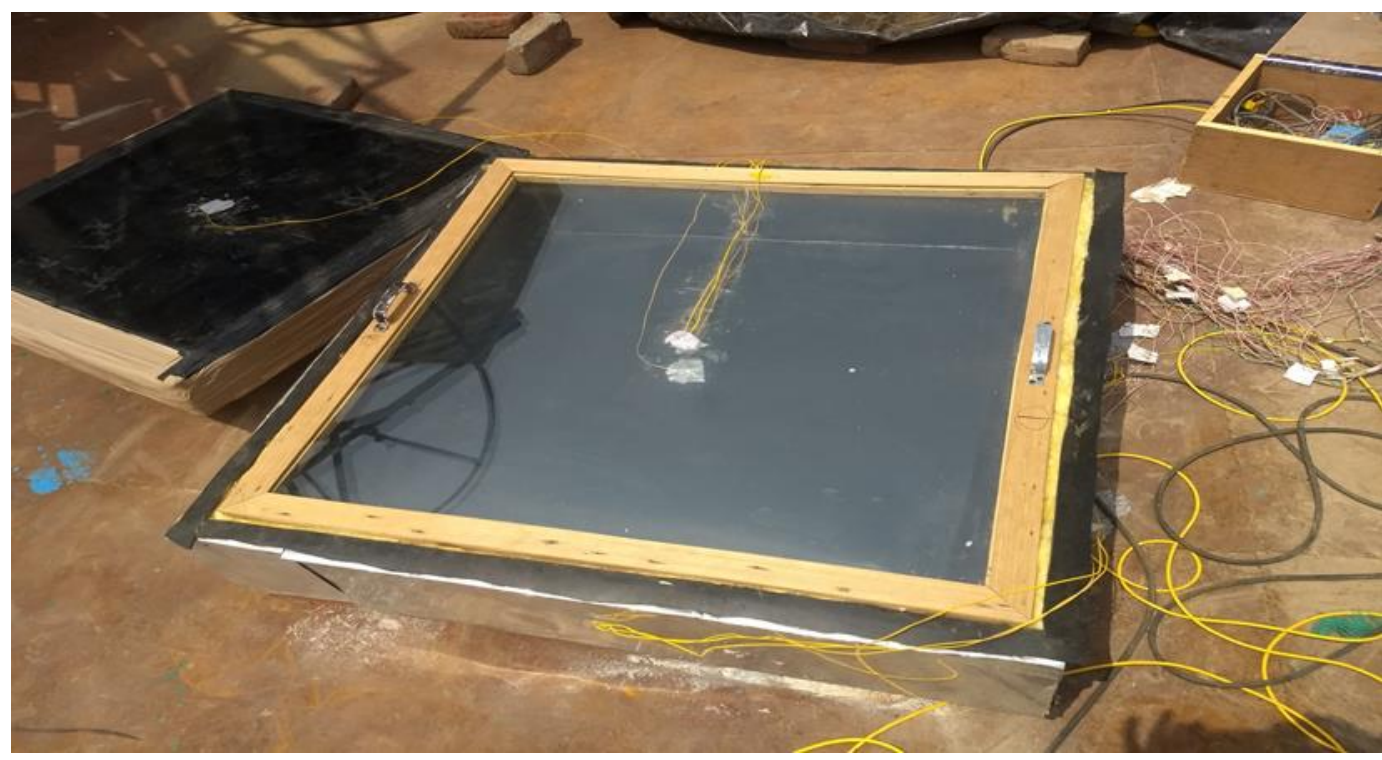

Fig.1. Experimental test setup along with plate at UPES, Dehradun

Table 1. Specifications of the test setup

\begin{tabular}{|l|l|}
\hline Material Size Box Wooden Board & $1.185 \times 1.175 \times 0.28 \mathrm{~m}$ \\
\hline Tray 24 Gauge Aluminum Sheet & $0.87 \times 0.87 \mathrm{~m}$ \\
\hline Glazing(Double) ordinary glass sheets & $4 \mathrm{~mm}$ thick \\
\hline Aperture area & $0.98 \times 0.98 \mathrm{~m}$ \\
\hline Air gap spacing between tray and inner glass & $98 \mathrm{~mm}$ \\
\hline Air gap spacing between inner glass and outer glass & $12 \mathrm{~mm}$ \\
\hline \multicolumn{2}{|c|}{ Test plate dimensions } \\
\hline Area exposed to sun (aluminum sheet ) & $870 \times 870 \mathrm{~mm}$ \\
\hline Thickness of asbestos sheet & $5 \mathrm{~mm}$ \\
\hline Thickness of insulation (3 layers) & $25 \mathrm{~mm}$ each \\
\hline
\end{tabular}

Table 2. Measuring instruments.

\begin{tabular}{|l|l|}
\hline \multicolumn{1}{|c|}{ Parameters } & \multicolumn{1}{c|}{ Measuring equipment } \\
\hline Solar insolation $(\mathrm{I})$ & Pyranometer \\
\hline Wind velocity $(\mathrm{V})$ & Ultrasonic wind sensor \\
\hline Plate temperature $\left(\mathrm{T}_{\mathrm{p})}\right.$ & K type thermocouple \\
\hline Outer glass temperature $\left(\mathrm{Tg}_{1}\right)$ & K type thermocouple \\
\hline Inner glass temperature $\left(\mathrm{Tg}_{2}\right)$ & K type thermocouple \\
\hline
\end{tabular}

\section{Calculation procedure}

Wind-heat transfer coefficient $\left(h_{w}\right)$

Based on the above-measured parameters wind heat transfer coefficient, bottom and side heat loss coefficient were evaluated.

In the present BIS model of box-type solar cooker, the effect of wind-heat transfer coefficient $\left(h_{w}\right)$ on the performance of solar cooker has not been considered. The wind heat transfer coefficient depends upon wind velocity $(V)$. To evaluate $h_{w}$ several correlations have been suggested in the literature. Most of these correlations are based on wind tunnel test whereas in actual situation (especially in outdoor conditions) the test conditions cannot always be represented by the wind tunnel conditions. 
Some of the relations available in literature are:

- Mc. Adams [52] suggested based on wind tunnel experiments

$$
h_{w}=5.7+3.8 V, \text { for } V \leq 5 m / s
$$

- Mullick et al. [21] carried out indoor experimental study for $h_{w}$, from the outer surface of flat horizontal surface, using an industrial fan to produce forced air flow. They concluded that the values of $h_{w}$ obtained by wind tunnel tests would be an underestimation and should not be employed under other conditions. They have proposed

$$
h_{w}=10.03+4.68 \mathrm{~V}
$$

- Kumar et al. [19] conducted outdoor experiments on unglazed aluminum blackened plate of size 925 $\mathrm{mm} \times 865 \mathrm{~mm} \times 2 \mathrm{~mm}$ in real environment and suggested the following correlation (for wind speed recorded at an interval of $1 \mathrm{sec}$ and averaged over wind speed at 10 minutes interval).

$$
\begin{aligned}
& h_{w}=7.15+3.19, \text { for } V \leq \\
& 1.12 \mathrm{~m} /
\end{aligned}
$$

The above values of the $h_{w}$ were compared with the value of wind heat transfer coefficient obtained from heat balance of the box type solar cooker setup using following formula.

$$
h_{w}=\frac{\left[\alpha p I-K i \frac{(T i b-T i b)}{t}-\sigma \epsilon p\left(T_{p}^{4}-T_{s}^{4}\right)-\operatorname{masCpas} \frac{d T_{a s}}{d t}-m i C i \frac{d T_{m i}}{d t}-m p C p \frac{d T_{p}}{d t}\right]}{T_{p}-T_{a}}
$$

The bottom and side loss coefficient were calculated and compared with the assigned value of $0.85 \mathrm{~W} / \mathrm{m}^{2 \circ} \mathrm{C}$ reported by Khan [53].

Bottom and side heat loss coefficient

The above assumed value of bottom and side heat loss coefficient was compared with the value obtained from heat balance of the set up using formula.

$$
U_{(b+s)}=\left(Q_{b}+Q_{s}\right) /\left(T_{p}-T_{a}\right) A_{s}
$$

A comparative analysis is performed for inner and outer glass cover temperatures using experimentally, measured values and the values of glass temperature obtained from Akhtar's correlations [54].

\section{Results and discussion}

Figure 2 shows the variation of plate temperature across various months of the year at the geographic location of Dehradun. Insolation seems to have a considerable effect on plate temperature. It is obvious from the fact that a higher value of insolation will result into higher plate temperature. The value of plate was measured to be a minimum of $313 \mathrm{~K}$ in the month of November corresponding to the highest value of $397 \mathrm{~K}$ during June. The value of insolation lies between $444 \mathrm{~W} / \mathrm{m} 2$ to $970 \mathrm{~W} / \mathrm{m} 2$ throughout the year.

In the present work, test information of unglazed test plate during the months JAN-DEC for a long time were utilized to evaluate wind-heat move coefficient. Wind speed was recorded at the site of investigations with a testing time of 1 second. Estimated wind speed was arrived at the midpoint of over a time of 10 minutes to give a delegate estimation of wind speed for that period. The heat transfer coefficient for the wind was assessed from equation (4) on various exploratory runs when conditions were near steady state. Tests were performed on an unglazed test plate of about $0.9 \mathrm{~m}$ square in size.

Moreover, there is a considerable difference in the values of wind-heat transfer coefficient ( $h w$ ) obtained from different correlations at the same wind velocity. The comparative study of the above correlations is shown in Figure.3. At certain wind velocities, Harples and Charlesworth [55] correlation gives the minimum value whereas the maximum value is obtained from the correlation proposed by the experimental data analysis using equation (4). The percentage difference is considerably higher at lower wind velocities, and it decreases with increasing velocities. 
Figure 3 shows the comparison between the average values of wind-heat transfer coefficient obtained during experimentation throughout the year in respect to the values of wind heat transfer coefficient calculated using different correlation suggested by Kumar et al. [19], Mc Adams [52], Harples and Charlesworth [55] and Sparro et al. [56], using the respective values of measure wind velocity. The average value of insolation and plate temperature for a particular month is calculated for comparison. It is observed from the figure that the values of $h_{w}$ increase from January to June and then decreases during experimentation and theoretical investigation. Experimental values were observed to be higher than the theoretical values resulted from various correlations. It shows that wind velocity has a considerable effect on the wind heat transfer coefficient. For correlation, the results of various investigations were normalized for a plate length of $0.9 \mathrm{~m}$.

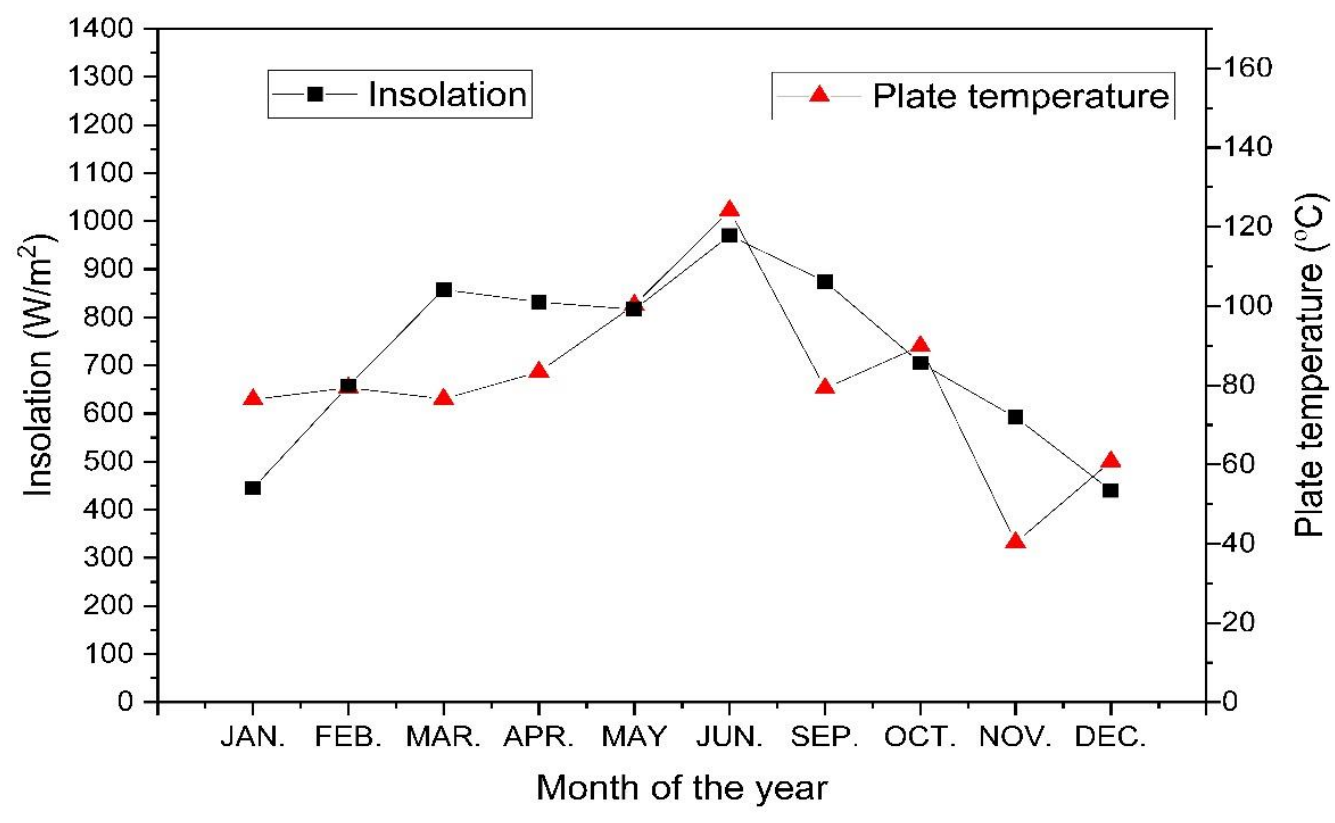

Fig.2. Variation of plate temperature with insolation during different months of year

Figure 4 depicts the variation of the summation of bottom and side heat loss coefficient $\left(U_{b+s}\right)$ across various months of the year and compared with assumed values [53], the value of loss coefficient varies between 0.4 to 0.5 throughout the year. It is observed that an average variation of $20 \%$ is observed between the calculated and assumed values throughout the year. There is an increase seen in the bottom and side heat loss coefficient from April to June because of the wind velocity factor. As seen in Figure 3 the wind heat transfer coefficient is higher in these months, thus the losses will be enhanced. The quantum of change is not seen to substantially influence during experimentation. 


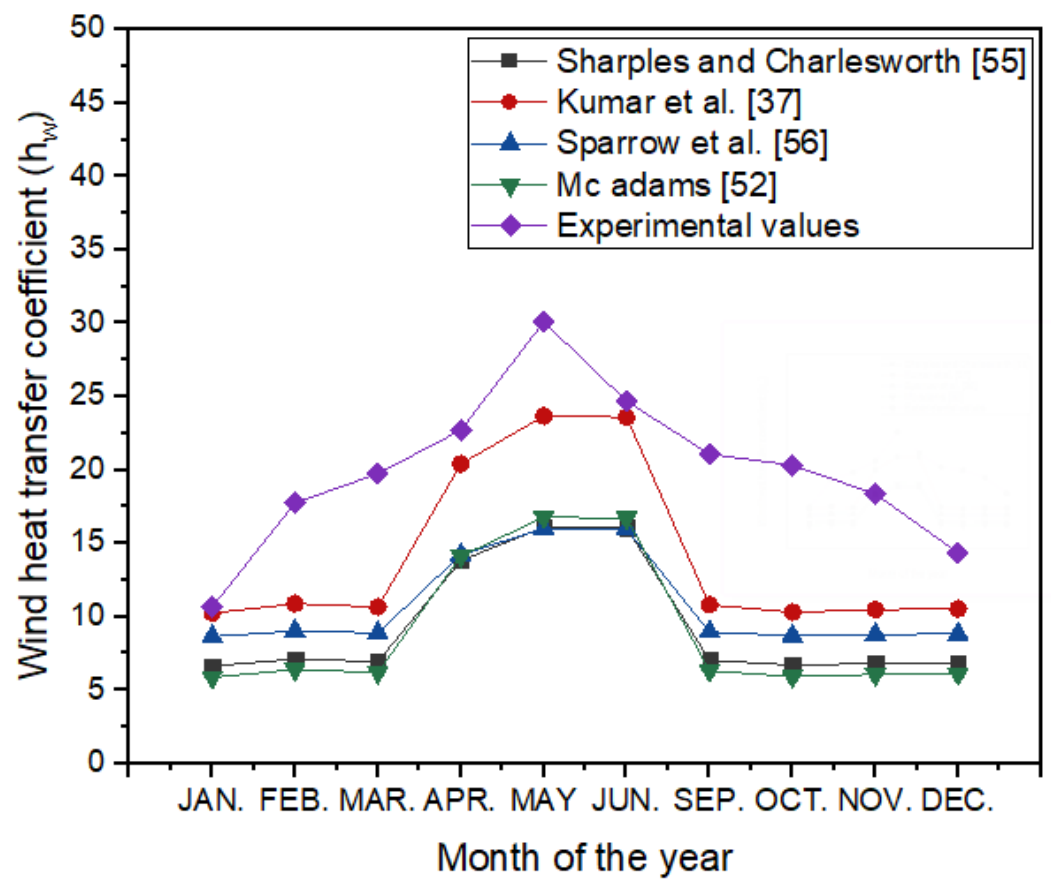

Fig. 3. Variation of wind heat transfer coefficient using different correlations

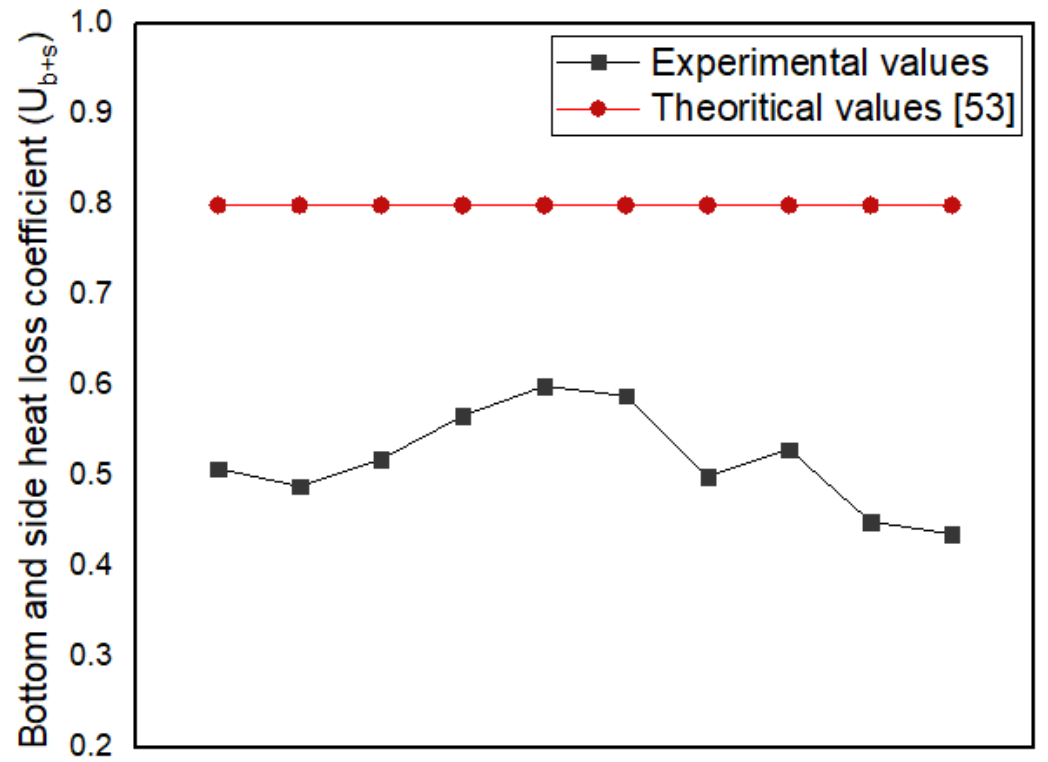

JAN. FEB. MAR. APR. MAY JUN. SEP. OCT. NOV. DEC.

Month of the year

Fig. 4. Variation of wind heat transfer coefficient using different correlations

Figure 5 shows the variation of outer glass cover temperature measured during different months of the year and compared with the values obtained using Akhtar [54] correlation. The outer glass cover temperature is highest in September and lowest in November. The variation between the experimentally measured values and calculated values lies between $4 \%$ to $20 \%$. The variation of inner glass cover temperature measured during different months of the year and compared with the values obtained using Akhtar [54] correlation is depicted in figure 6. The inner glass cover temperature is highest in the month of September and lowest in the month of November. The variation between the experimentally measured values and calculated values lies between $3 \%$ to $20 \%$. 


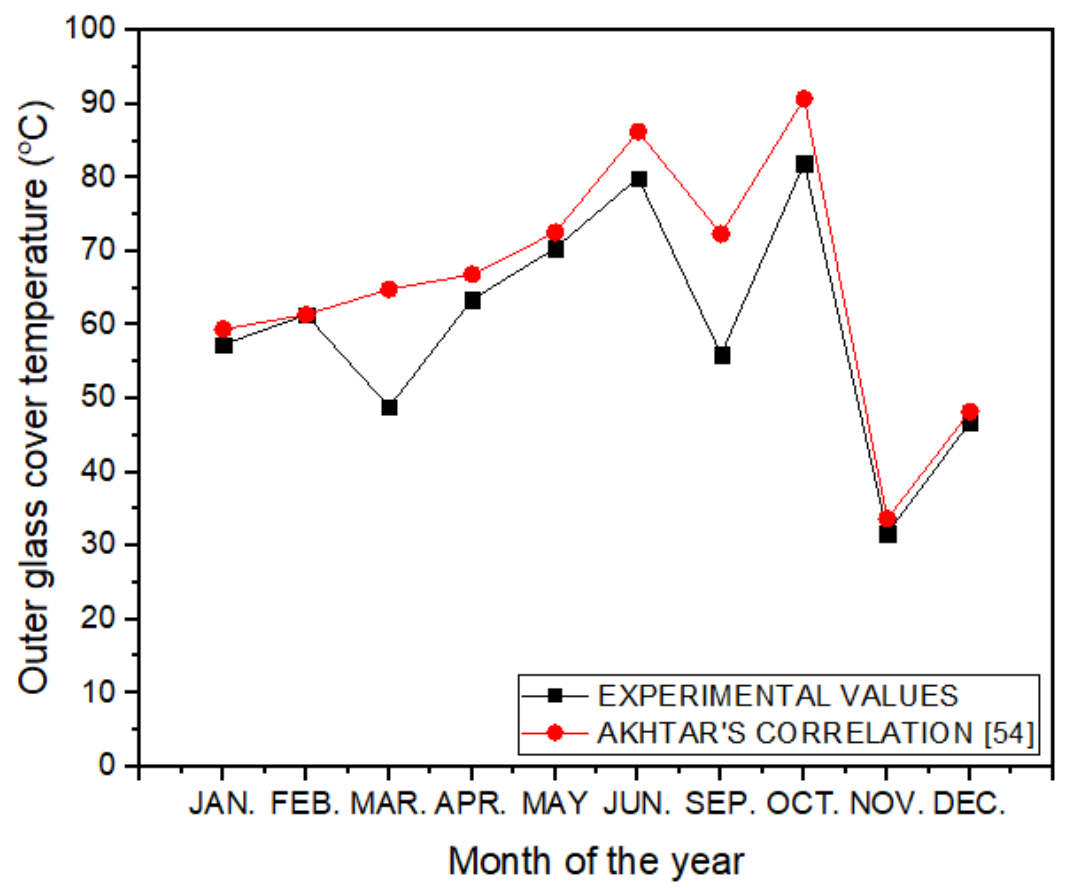

Fig. 5. Variation of experimental and predicted outer glass cover temperature

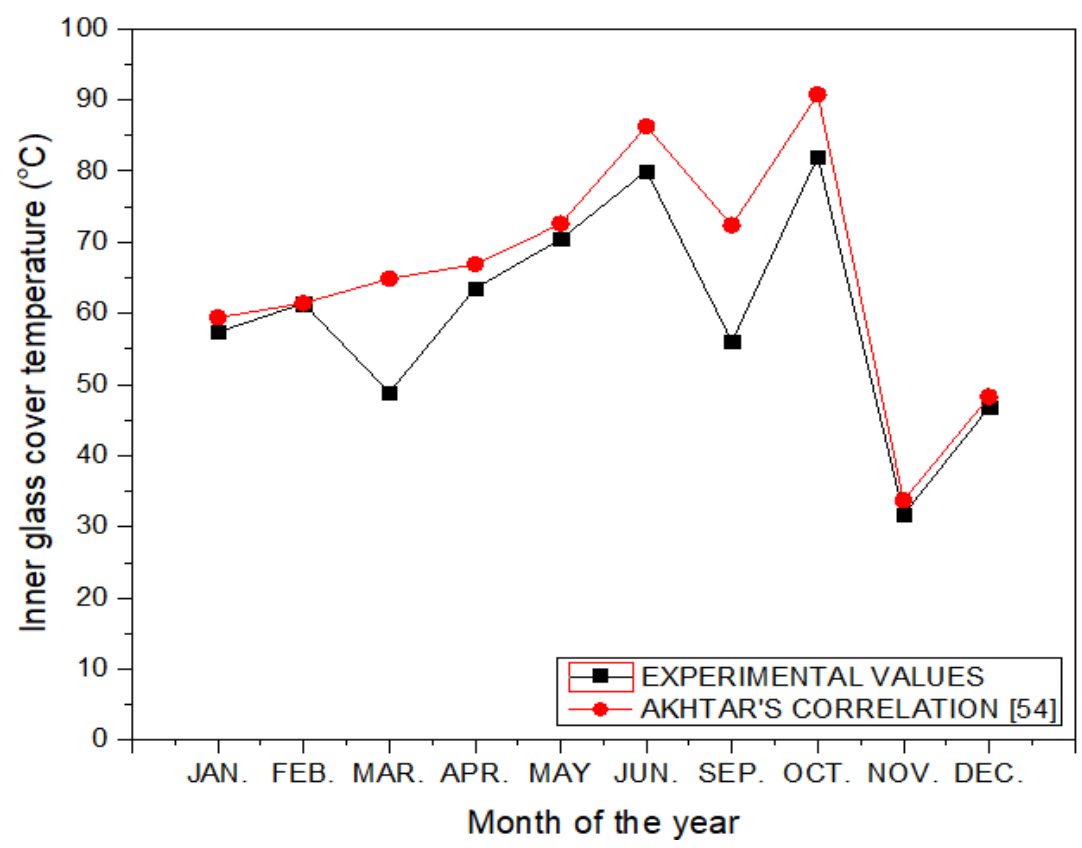

Fig. 6 Variation of experimental and predicted inner glass cover temperature

\section{Conclusion}

An extensive review was carried out to determine the testing standards for the solar cooker as well as the parameters that determine the performance of the cooker. Finally, comparison of experimental data with that of correlations data of selected climatic and operating variables was carried out. The wind heat transfer coefficient, side and bottom heat loss coefficient, outer glass cover temperature and inner glass cover temperature data was compared with that of the standard correlations. It was revealed that there was a deviation of a maximum $20 \%$ for all the selected parameters, which can be in the acceptable range but leads to an increase the inaccuracy of the results. Therefore, it is suggested that all these parameters should be calculated based on the geometry of the cooker and the geographical location of the experimentation to get accurate results. It is concluded that the geographical location plays a dominating role in the performance of the cooker and the operating parameters should be calculated rather than placing correlation values. 


\section{Conflict of interest}

There are no conflicts to declare.

\section{Acknowledgements}

This research has not been supported by any external funding.

\section{References}

[1] Volunteers Technical In Assistance, Solar Cooker Construction Manual, 7 th, Mt. Rainier, Md. (USA) VITA, 1981.

[2] T.E. Bowman, J.H. Blatt, Solar Cookers, History, Design, Fabrication, Testing and Evaluation, Florida Institute of Technology, Florida, 1978.

[3] H.P. Garg, B. Bandyopadhyay, G. Datta, Mathematical modelling of the performance of a solar cooker, Appl. Energy. 14 (1983) 233-239. https://doi.org/10.1016/0306-2619(83)90066-1.

[4] J.S. Vaishya, T.C. Tripathi, D. Singh, R.H. Bhawalkar, M.S. Hegde, A hot box solar cooker: Performance analysis and testing, Energy Convers. Manag. 25 (1985) 373-379. https://doi.org/10.1016/01968904(85)90057-3.

[5] T.C. Kandpal, S.S. Mathur, The economics of box-type solar cookers, Energy Convers. Manag. 26 (1986) 233-235. https://doi.org/10.1016/0196-8904(86)90060-9.

[6] S.C. Mullick, T.C. Kandpal, A.K. Saxena, Thermal test procedure for box-type solar cookers, Sol. Energy. 39 (1987) 353-360. https://doi.org/10.1016/S0038-092X(87)80021-X.

[7] S.A. Channiwala, N.I. Doshi, Heat loss coefficients for box-type solar cookers, Sol. Energy. 42 (1989) 495501. https://doi.org/10.1016/0038-092X(89)90050-9.

[8] B.A. Jubran, M.A. Alsaad, Parametric study of a box-type solar cooker, Energy Convers. Manag. 32 (1991) 223-234. https://doi.org/10.1016/0196-8904(91)90126-4.

[9] S.K. Samdarshi, S.C. Mullick, Analytical equation for the top heat loss factor of a flat-plate collector with double glazing, J. Sol. Energy Eng. Trans. ASME. 113 (1991) 117-122. https://doi.org/10.1115/1.2929955.

[10] H. Suharta, P.D. Sena, A.M. Sayigh, Komarudin, The social acceptibility of solar cooking in Indonesia, Renew. Energy. 16 (1999) 1151-1154. https://doi.org/10.1016/s0960-1481(98)00460-1.

[11] E.R. Pejack, Mathematical model of the thermal performance of box-type solar cookers, Renew. Energy. 1 (1991) 609-615. https://doi.org/10.1016/0960-1481(91)90004-9.

[12] S.C. Mullick, T.C. Kandpal, S. Kumar, Thermal test procedure for a paraboloid concentrator solar cooker, Sol. Energy. 46 (1991) 139-144. https://doi.org/10.1016/0038-092X(91)90087-D.

[13] A. Kumar, V.V.N. Kishor, Development and Testing of Improved Solar Rice Cooker, J. Sol. Energy Soc. India. 4 (1994) 87-91.

[14] T.C. Thulasi Das, S. Karmakar, D.P. Rao, Solar box-cooker: Part I-Modeling, Sol. Energy. 52 (1994) 265272. https://doi.org/10.1016/0038-092X(94)90493-6.

[15] T.C. Thulasi Das, S. Karmakar, D.P. Rao, Solar box-cooker: Part II- Analysis and simulation, Sol. Energy. 52 (1994) 273-282. https://doi.org/10.1016/0038-092X(94)90494-4.

[16] S.M.A. Ibrahim, M.K. El-Reidy, The performance of a solar cooker in Egypt, Renew. Energy. 6 (1995) 10411050. https://doi.org/10.1016/0960-1481(95)00088-7.

[17] A.A. El-Sebaii, R. Domański, M. Jaworski, Experimental and theoretical investigation of a box-type solar cooker with multi-step inner reflectors, Energy. 19 (1994) 1011-1021. https://doi.org/10.1016/03605442(94)90088-4.

[18] G. Naik, G. Sharan, Assessing Consumer Preference for Product Features Selection: Solar Cookers, Vikalpa. 22 (1997) 49-54. https://doi.org/10.1177/0256090919970406.

[19] S.C. Mullick, T.C. Kandpal, S. Kumar, Testing of box-type solar cooker: Second figure of merit F2 and its variation with load and number of pots, Sol. Energy. 57 (1996) 409-413. https://doi.org/10.1016/S0038092X(96)00116-8.

[20] M. Hussain, K.C. Das, A. Huda, The performance of a box-type solar cooker with auxiliary heating, Renew. Energy. 12 (1997) 151-155. https://doi.org/10.1016/S0960-1481(97)00037-2.

[21] S.S. Nandwani, J. Steinhart, H.M. Henning, M. Rommel, V. Wittwer, Experimental study of multipurpose solar hot box at Freiburg, Germany, Renew. Energy. 12 (1997) 1-20. https://doi.org/10.1016/S09601481(97)00014-1.

[22] E.H. Amer, J.K. Nayak, G.K. Sharma, Transient method for testing flat-plate solar collectors, Energy Convers. Manag. 39 (1998) 549-558. https://doi.org/10.1016/S0196-8904(97)10014-0.

[23] E.H. Amer, J.K. Nayak, G.K. Sharma, Transient test methods for flat-plate collectors: Review and experimental evaluation, Sol. Energy. 60 (1997) 229-243. https://doi.org/10.1016/S0038- 
092X(97)00023-6.

[24] P.A. Funk, D.L. Larson, Parametric model of solar cooker performance, Sol. Energy. 62 (1998) 63-68. https://doi.org/10.1016/S0038-092X(97)00074-1.

[25] A. Gaur, O.P. Singh, S.K. Singh, G.N. Pandey, Performance study of solar cooker with modified utensil, Renew. Energy. 18 (1999) 121-129. https://doi.org/10.1016/S0960-1481(98)00762-9.

[26] E. Biermann, M. Grupp, R. Palmer, Solar cooker acceptance in South Africa: Results of a comparative field-test, Sol. Energy. 66 (1999) 401-407. https://doi.org/10.1016/S0038-092X(99)00039-0.

[27] N. Akhtar, S.C. Mullick, Correlations for surface temperatures of the glass cover for estimation of heattransfer coefficients in upward heat-flow in solar collectors with single glazing, J. Sol. Energy Eng. Trans. ASME. 121 (1999) 201-206. https://doi.org/10.1115/1.2888167.

[28] P.A. Funk, Evaluating the international standard procedure for testing solar cookers and reporting performance, Sol. Energy. 68 (2000) 1-7. https://doi.org/10.1016/S0038-092X(99)00059-6.

[29] S.D. Sharma, D. Buddhi, R.L. Sawhney, A. Sharma, Design, development and performance evaluation of a latent heat storage unit for evening cooking in a solar cooker, Energy Convers. Manag. 41 (2000) 1497-1508. https://doi.org/10.1016/S0196-8904(99)00193-4.

[30] H. Suharta, A.M. Sayigh, K. Abdullah, K. Mathew, Comparison of three types of Indonesian solar box cookers, Renew. Energy. 22 (2001) 379-387. https://doi.org/10.1016/S0960-1481(00)00062-8.

[31] S.C. Mullick, S.Y. Khan, B.K. Chourasia, Semi log plot and an approximate expression to find second figure of merit of box type solar cookers, in: Proc. Sol. World Congr. 2005 Bringing Water to World, Incl. Proc. 34th ASES Annu. Conf. Proc. 30th Natl. Passiv. Sol. Conf., Orlando, Florida, USA, 2005: pp. 1713-1716.

[32] S. Shaw, Development of a comparative framework for evaluating the performance of solar cooking devices, Comb. Ergon. Therm. Qual. Data into an Understandable, Reprod. Rigorous Test. Method, NY, USA. (2002) 1-53.

[33] O. V. Ekechukwu, N.T. Ugwuoke, Design and measured performance of a plane reflector augmented boxtype solar-energy cooker, Renew. Energy. 28 (2003) 1935-1952. https://doi.org/10.1016/S09601481(03)00004-1.

[34] E.H. Amer, Theoretical and experimental assessment of a double exposure solar cooker, Energy Convers. Manag. 44 (2003) 2651-2663. https://doi.org/10.1016/S0196-8904(03)00022-0.

[35] A.H. Algifri, H.A. Al-Towaie, Efficient orientation impacts of box-type solar cooker on the cooker performance, Sol. Energy. 70 (2001) 165-170. https://doi.org/10.1016/S0038-092X(00)00136-5.

[36] N.M. Nahar, J.P. Gupta, P. Sharma, A novel solar cooker for animal feed, Energy Convers. Manag. 37 (1996) 77-80. https://doi.org/10.1016/0196-8904(95)00160-F.

[37] S. Kumar, S.C. Mullick, Wind heat transfer coefficient in solar collectors in outdoor conditions, Sol. Energy. 84 (2010) 956-963. https://doi.org/10.1016/j.solener.2010.03.003.

[38] S. Kumar, Estimation of design parameters for thermal performance evaluation of box-type solar cooker, Renew. Energy. 30 (2005) 1117-1126. https://doi.org/10.1016/j.renene.2004.09.004.

[39] H. Kurt, K. Atik, M. Özkaymak, Z. Recebli, Thermal performance parameters estimation of hot box type solar cooker by using artificial neural network, Int. J. Therm. Sci. 47 (2008) 192-200. https://doi.org/10.1016/j.ijthermalsci.2007.02.007.

[40] S.S. Nandwani, Design, construction and study of a hybrid solar food processor in the climate of Costa Rica, Renew. Energy. 32 (2007) 427-441. https://doi.org/10.1016/j.renene.2006.01.019.

[41] K. Schwarzer, M.E. Vieira da Silva, Solar cooking system with or without heat storage for families and institutions, Sol. Energy. 75 (2003) 35-41. https://doi.org/10.1016/S0038-092X(03)00197-X.

[42] A. Harmim, M. Boukar, M. Amar, Experimental study of a double exposure solar cooker with finned cooking vessel, Sol. Energy. 82 (2008) 287-289. https://doi.org/10.1016/j.solener.2007.10.008.

[43] M. Grupp, M. Balmer, B. Beall, H. Bergler, J. Cieslok, D. Hancock, G. Schröder, On-line recording of solar cooker use rate by a novel metering device: Prototype description and experimental verification of output data, Sol. Energy. 83 (2009) 276-279. https://doi.org/10.1016/j.solener.2008.08.002.

[44] M.M. Garba, I.M. Danmallam, Performance evaluation of rectangular and square type box type cooker, Niger. J. Renew. Energy. 16 (2011) 120-126.

[45] D.Y. Dasin, D. Habou, I. Rikoto, Performance evaluation of parabolic solar concentrator against international standard procedure in the tropical Environment, Niger. J. Renew. Energy. 15 (2011) 20-22.

[46] P.M. Cuce, Box type solar cookers with sensible thermal energy storage medium: A comparative experimental investigation and thermodynamic analysis, Sol. Energy. 166 (2018) 432-440. https://doi.org/10.1016/j.solener.2018.03.077.

[47] S. Geddam, G.K. Dinesh, T. Sivasankar, Determination of thermal performance of a box type solar cooker, Sol. Energy. 113 (2015) 324-331. https://doi.org/10.1016/j.solener.2015.01.014. 
[48] M. Collares-Pereira, A. Cavaco, A. Tavares, Figures of merit and their relevance in the context of a standard testing and performance comparison methods for solar box - Cookers, Sol. Energy. 166 (2018) 21-27. https://doi.org/10.1016/j.solener.2018.03.040.

[49] S. Bhavani, S. Shanmugan, P. Selvaraju, C. Monisha, V. Suganya, Fuzzy interference treatment applied to energy control with effect of box type affordable solar cooker, in: Mater. Today Proc., 2019: pp. 12801290. https://doi.org/10.1016/j.matpr.2019.06.590.

[50] V. Kodur, P. Kumar, M.M. Rafi, Fire hazard in buildings: review, assessment and strategies for improving fire safety, PSU Res. Rev. 4 (2019) 1-23. https://doi.org/10.1108/prr-12-2018-0033.

[51] BIS Standard on Solar Cookers Parts I, II \& III, (2000).

[52] W.H. McAdams, Heat transmission, McGraw-Hill, New York, USA, 1954.

[53] S.Y. Khan, Thermal Performance Evaluation of Solar Box Cookers. Ph. D. Thesis, (2004).

[54] N. Akhtar, S.C. Mullick, Computation of glass-cover temperatures and top heat loss coefficient of flatplate solar collectors with double glazing, Energy. 32 (2007) 1067-1074. https://doi.org/10.1016/j.energy.2006.07.007.

[55] S. Sharples, P.S. Charlesworth, Full-scale measurements of wind-induced: Convective heat transfer from a roof mounted flat plate solar collector, Sol. Energy. 62 (1998) 69-77. https://doi.org/10.1016/S0038092X(97)00119-9.

[56] E.M. Sparrow, J.W. Ramsey, E.A. Mass, Effect of finite width on heat transfer and fluid flow about an inclined rectangular plate, J. Heat Transfer. 101 (1979) 199-204. https://doi.org/10.1115/1.3450946. 